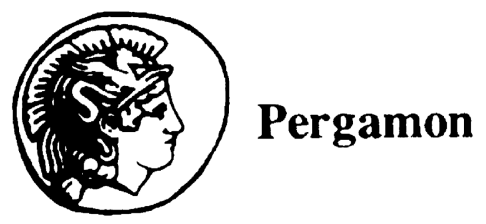

Available online at www.sciencedirect.com

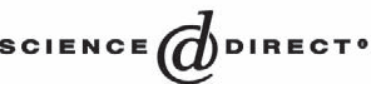

ADDICTIVE BEHAVIORS

Addictive Behaviors 28 (2003) 1533-1554

\title{
Drugs of abuse and the elicitation of human aggressive behavior
}

\author{
Peter N.S. Hoaken ${ }^{\mathrm{a}, *}$, Sherry H. Stewart ${ }^{\mathrm{b}}$ \\ ${ }^{a}$ Department of Psychology, University of Western Ontario, London ON, Canada N6A 5C2 \\ ${ }^{\mathrm{b}}$ Department of Psychology and Psychiatry, Dalhousie University, Halifax, Nova Scotia, Canada
}

\begin{abstract}
The drug-violence relationship exists for several reasons, some direct (drugs pharmacologically inducing violence) and some indirect (violence occurring in order to attain drugs). Moreover, the nature of that relationship is often complex, with intoxication, neurotoxic, and withdrawal effects often being confused and/or confounded. This paper reviews the existing literature regarding the extent to which various drugs of abuse may be directly associated with heightened interpersonal violence. Alcohol is clearly the drug with the most evidence to support a direct intoxication-violence relationship. The literatures concerning benzodiazepines, opiates, psychostimulants, and phencyclidine (PCP) are idiosyncratic but suggest that personality factors may be as (or more) important than pharmacological ones. Cannabis reduces likelihood of violence during intoxication, but mounting evidence associates withdrawal with aggressivity. The literature on the relationship between steroids and aggression is largely confounded, and between 3,4-methylenedioxymethamphetamine (MDMA) and aggression insufficient to draw any reasonable conclusions. Conclusions and policy implications are briefly discussed.
\end{abstract}

(C) 2003 Elsevier Ltd. All rights reserved.

Keywords: Aggressive behavior; Drugs of abuse; Violence

The relationship between drug use and/or abuse and human interpersonal violence is profound, costly, and undeniable. Research indicates that substance abuse disorders rate among the most prevalent psychiatric disorders, for 1 month, yearly, or lifetime diagnoses (Eaton, Kramer, Anthony, Drymon, \& Locke, 1989). While some make the case that drug use

\footnotetext{
* Corresponding author.

E-mail address: phoaken@uwo.ca (P.N.S. Hoaken).
} 
and abuse is increasingly better understood and that valid and effective treatment approaches are increasingly available, it likely remains the case that the majority of drug abusers do not receive adequate treatment, become enmeshed in the legal system, seek alternative approaches, or never seek and/or receive treatment. Thus, the problem of drug-related aggression is likely to continue to prove problematic to clinicians and lawmakers alike.

Any discussion of the relationship between drugs and "aggression" or "violence" should start by defining what is meant by these latter terms. Human aggression is a multidimensional construct that defies simple definition, but for the purposes of this paper, we will utilize a slight modification of the definition of Baron (1977; Baron \& Richardson, 1994): "Aggression is any form of behavior directed toward the goal of harming or injuring another living being who is motivated to avoid such treatment." The terms "aggression" and "violence," while essentially interchangeable, do differ inasmuch as the former is predominantly an empirical term and the latter predominantly a forensic term; that is, in the following literature review, studies that utilize drug administration and a laboratory measure tend to use the term "aggression," whereas investigations of individuals who have come into contact with law enforcement after drug consumption tend to use the term "violence." Our differential use of these two terms, therefore, reveals something about the nature of the study in question and does not imply that the constructs are substantively different. To be increasingly specific, we will use the term "aggression" in regards to physical harm or injury observed between animals in animal studies and "violence" and "interpersonal aggression" (interchangeably) to denote aggression involving physical harm or injury that occurs between two or more human beings in the human literature.

As has been previously articulated (Pihl \& Hoaken, 1997), there are at least four differential, but not necessarily mutually exclusive, reasons that the relationship between drugs and aggression exists. Specifically, violent crimes can be committed to gain access to drugs or resources to purchase drugs; violence is often a necessary means of resolving disputes in an illegal and thus inherently unregulated and ruleless business. In addition, violent behavior and drug use can be the result of the same factors (e.g., high sensation seeking) and exist coincidentally. The last putative contributor to the drug-aggression relationship, and the predominant focus of this paper, is that certain drugs can increase the likelihood of violence because of their direct effects on the individual. We will specify these direct effects into three categories: direct pharmacological effects (intoxication), neurotoxic effects (damage caused by prolonged use), or withdrawal effects (abstinence immediately following prolonged use).

In the case of intoxication, previous authors (Pihl \& Hoaken, 2002; Pihl \& Peterson, 1995) have conceptualized four, of perhaps many, physiological effects of drugs on an individual that should increase the likelihood of violence. Although not considered to be either mutually exclusive or collectively exhaustive, these four types of effects provide a framework in which we will discuss the different means by which direct pharmacological effects of different drugs may heighten aggression.

The first of these putative explanatory pharmacological effects is an alteration of the psychomotor system in such a way that excitation and reward are enhanced. Psychomotor stimulants potentiate motor behaviors, including approach, sensation seeking, and/or attack 
behaviors, which would not ordinarily be manifested. Psychomotor stimulant properties therefore appear to potentiate violence in humans by means of amplified behaviors that could be characterized as risky. The second pharmacological effect is an alteration of the anxiety and/or threat system. Typically, individuals learn as children that heightened aggression is linked with increased likelihood of punishment. By virtue of this, cues that signal the need to become aggressive typically elicit anxiety, which in turn decreases the likelihood of aggression. Some drugs, however, dampen these internal inhibiting mechanisms, leading to increased probability of the aggressive response. The third mechanism is an alteration of the pain system. This mechanism is idiosyncratic inasmuch as it has been argued both that drugs that increase and drugs that decrease pain sensitivity may increase the likelihood of aggression. In terms of drugs that diminish pain sensitivity, it is possible that this effect may diminish the normally punishing aspects of pain one may experience in a provocative interaction. In terms of drugs that increase pain sensitivity, this may operate in such a way that saliency of provocative stimuli is increased. Defensive aggression is an unconditioned response; drugs that heighten pain sensitivity therefore increase likelihood of defensive aggression. The last mechanism is an alteration of the certain higher order cognitive capacities, what one could conceive of as the cognitive control center, which normally modulates the general motivational state. Certain drugs may interfere with the cognitive capacities which underlie planning, the formulation of behavioral strategies, and the initiation and maintenance of goal-directed behavior in response to external and internal regulatory cues.

Clearly, any drug can affect the functioning of one or more of these hypothesized systems. What follows is a discussion of the prominent drugs of abuse and the evidence that each is related to heightened human aggressive behavior. In instances where the evidence for a relationship between the drug in question and aggression is strong, putative explanatory mechanisms will be discussed in the context of the four mechanisms described above. When relevant studies are available, we will also discuss the drug-aggression relationship in terms of the effects of chronic use (i.e., neurotoxic effects) and/or withdrawal syndrome. We begin this review with alcohol for three reasons: (1) it is the drug most frequently used and most frequently abused; (2) it is somewhat unique inasmuch as it affects all of the aforementioned systems; and (3) it is by far the drug most likely to be associated with heightened likelihood of interpersonal violence.

\section{Alcohol}

Conventional wisdom tells us that individuals who are under the influence of alcohol will act aggressively. This is a situation in which conventional wisdom is likely correct - crime studies consistently implicate alcohol intoxication as one of the most significant factors in violent behavior. In large-scale review of 26 studies, involving 11 countries, it was determined that $62 \%$ of offenders convicted of a violent crime had been consuming alcohol shortly before committing the crime in question (Murdoch, Pihl, \& Ross, 1990). Alcohol was more than twice as likely to be a contributing factor to violent crimes than nonviolent crimes, 
and in those studies that measured level of alcohol, violence was associated with heavy drinking. Another recent study, conducted with homicidal offenders in Finland, indicated a relationship between severity of alcohol use and violence. In this sample, $39.2 \%$ of male offenders and $32.1 \%$ of female offenders met DSM-III-R criteria for alcoholism; the next highest rate for an Axis I disorder was approximately $6 \%$ for schizophrenia (Eronen, Hakola, $\&$ Tiihonen, 1996). The alcohol-aggression relationship has been demonstrated in adult men and women (Hoaken \& Pihl, 2000; Giancola et al., 2002), adolescents (Dembo, Pacheco, Schmeidler, Fischer, \& Cooper, 1997), different ethnic groups (Murdoch et al., 1990; Valdes, Kaplan, Curtis, \& Yin, 1995), and mentally disordered and nondisordered individuals (Hodgins, Mednick, Brennan, Schulsinger, \& Engberg, 1996). Alcohol consumption has also been associated with a wide range of types of violence, including but not limited to sexual aggression (Parks \& Zetes-Zanatta, 1999; Seto \& Barbaree, 1995; Testa, 2002), family and marital violence (Caetano, Schafer, Fals-Stewart, O'Farrell, \& Miller, 2003; Leonard \& Jacob, 1988; Leonard \& Senchack, 1996), child abuse (Kaufman-Kantor \& Straus, 1990), and suicide (Brent, Perper, \& Allman, 1987).

While crime studies of this sort are purely correlational and thus open to interpretation, manipulative controlled laboratory studies have confirmed alcohol's role in aggressive behavior. There are now several relevant meta-analyses of experimental studies of the alcohol-aggression relationship, all of them concluding that even moderate doses of alcohol increase a participant's likelihood of acting aggressively (Bushman, 1993, 1996; Bushman \& Cooper, 1990; Hull \& Bond, 1986; Ito, Miller, \& Pollock, 1996; Steele \& Southwick, 1985).

That this relationship exists appears incontrovertible. What are less consistently agreed upon are the reasons for the relationship and why only some individuals respond aggressively subsequent to alcohol consumption. Because of the enormous individual variability in terms of the aggression-eliciting properties of alcohol and because of the inconsistencies in the literature, most researchers now view the relationship between alcohol consumption and aggression as particularly complex and likely the product of several interactive factors (Chermack \& Giancola, 1997; Pihl \& Hoaken, 2002). Pharmacological, contextual, situational, and perhaps most importantly individual difference factors have been identified, which moderate the alcohol-aggression relationship in humans (for a review, see Pihl, Assaad, \& Hoaken, 2003). Nonetheless, a large body of literature suggests that alcohol has pharmacological effects on the four aforementioned systems, and as such we will review these now.

\subsection{Alcohol-aggression relationship and psychomotor stimulant effects}

One means by which alcohol elicits aggression relates to its rewarding properties (Pihl \& Peterson, 1995; Pihl, Peterson, \& Lau, 1993). It is plainly evident that alcohol has rewarding properties, especially soon after consumption, while it is still being absorbed (i.e., during the ascending limb of the blood-alcohol concentration curve). These rewarding properties are simplistically comparable to those of stimulants such as cocaine and amphetamine and appear pharmacologically mediated by the dopaminergic system (Boileau et al., 2003; Gessa, Muntone, Collu, Vargiu, \& Mereu, 1985). Also in common with these other drugs, low and 
moderate doses of alcohol produce stimulation, manifested in a variety of ways, including increased heart rate (Conrod, Peterson, Pihl, \& Mankowski, 1997; Rush et al., 1993; Stewart, Loba, Blackburn, Ellery, \& Klein, in press). These psychomotor stimulant effects may also increase the likelihood of aggression in that there is an increase in sensation seeking and impulsivity, as well as increases in novelty seeking and/or approach behaviors. These alterations may lead to increases in confrontational and provocative behaviors on the part of the inebriate, which may lead to either proactive or reactive aggression (Pihl \& Peterson, 1995).

\subsection{Alcohol-aggression and interrupted threat-detection}

That alcohol consumption can alleviate subjective feelings of stress is well known. This effect, not unlike that of benzodiazepines or barbiturates, appears related to alcohol's effects on gamma aminobutyric acid (GABA), the main inhibitory neurotransmitter. Specifically, theorists have suggested that alcohol increases firing of GABAergic neurons, increasing their inhibitory influence, particularly in prefrontal and limbic structures that mediate perception of threat (Gray, 1982, 1987).

The capacity of alcohol to produce stress-response dampening has been implicated in the alcohol-aggression relationship by several researchers (Ito et al., 1996; Pihl \& Peterson, 1995; Sayette, 1993a). According to this hypothesis, if alcohol is consumed prior to a provocative or anxiety-eliciting event, its anxiolytic properties will reduce the likelihood of an appropriate appraisal of that event. Therefore, this is essentially a disinhibition model; fear is diminished and as a result, the inhibitory effects that fear usually exerts on aggressive behavior are inhibited. Support for this hypothesis exists in the literatures from both work with animals and humans.

A large literature demonstrates that alcohol relatively infrequently heightens aggression in laboratory animals, especially rodents (Berry \& Smoothy, 1986). However, in the specific circumstances in which these animals do become aggressive in response to alcohol (Blanchard, Hori, Blanchard, \& Hail, 1987), they also demonstrate an "anxiolytic profile" characterized by decreased proxemic avoidance, decreased risk assessment, and reduced suppression of nondefensive behaviors such as eating and drinking (Blanchard, Blanchard, \& Rodgers, 1991). Moreover, alcohol administration greatly increases rodent locomotion towards a threat (for example, a compartment containing a cat; for a review, see Blanchard, Veniegas, Elloran, \& Blanchard, 1993).

In terms of the literature with humans, several studies have demonstrated the ability of alcohol to disrupt threat detection (for a review, see Sayette, 1993b), and as previously noted, a voluminous literature demonstrates the alcohol-aggression relationship. Taylor et al. (1976) have demonstrated that drugs other than alcohol which are thought to have "anxiolytic" effects (e.g., benzodiazepines, barbiturates) also heighten aggression in humans (Chermack \& Taylor, 1993; Gantner \& Taylor, 1988). Perhaps the most compelling support for this hypothesis comes from a recent study from our group in which the extent to which alcohol dampened the cardiovascular stress response was found to at least partially mediate the alcohol-aggression relationship in a sample of 64 adult male and female participants 
(Hoaken, Campbell, Stewart, \& Pihl, 2003). Specifically, those participants who showed the greatest amount of cardiovascular stress response dampening to alcohol administration were also the most likely to act aggressively on the Taylor (1967) aggression paradigm while intoxicated.

\subsection{Alcohol-aggression relationship and alterations of the pain system}

Pihl et al. (1993) have suggested that alcohol's effects on pain sensitivity may also be consequential in the elicitation of aggression. The theorized relationship among alcohol, the pain system, and aggression is a complex one. On one hand, it is widely accepted that alcohol has analgesic effects; in fact, at one time, it was used as a surgical anaesthetic (Mullin \& Luckhardt, 1934; Wolff, Hardy, \& Goodell, 1942). In light of this, it could be surmised that alcohol's relationship with heightened aggression is simply that the analgesic properties block the normally punishing painful aspects of an aggressive altercation.

However, this theory is likely incorrect. Alcohol's effects on pain sensitivity are largely dose and individual dependant and moreover differ greatly during absorption and elimination of alcohol. At moderate dosages and on the rising limb of the blood-alcohol concentration curve, alcohol has been shown to actually increase ratings of pain sensitivity in humans (Gustafson, 1985). This is consistent with animal work, which has demonstrated lowered pain thresholds in alcohol-intoxicated rats (Gray, 1982). Thus, the relationship among alcohol, pain, and aggression may be paradoxical in nature. Alcohol may contribute to aggression simply by increasing reactivity to pain and correspondingly the significance of provocation. Because defensive aggression is an unconditioned response, alcohol's heightening of pain sensitivity may therefore increase likelihood of defensive aggression (Pihl et al., 1993). Moreover, one study demonstrated that the subjective experience of pain heightens selfreported irritation, annoyance, and anger and objectively increases aggression towards another, even if the source of pain cannot be attributed to this other person (Berkowitz \& Thome, 1987).

\subsection{Alcohol-aggression relationship and cognitive interference}

It can be argued that many of the hypotheses over the years that have purported to explain the alcohol-aggression relationship are inherently cognitive in nature. In each of them, alcohol is said to interfere with the appraisal of something; what differs among them is what it is that is being appraised, be it the self (Hull, 1981), behavior of others (Sayette, Wilson, \& Elias, 1993), central versus peripheral environmental detail (Steele \& Josephs, 1990), instigative versus inhibitory cues (Taylor \& Leonard, 1983), or something other. As such, it appears reasonable to suggest that the aggression-eliciting effects of alcohol are putatively metacognitive; i.e., involving the interference of perhaps many elements of cognition (Giancola, 2000).

Until recently, the extent to which alcohol interfered with various aspects of cognitive functioning was surprisingly underinvestigated; in fact, the majority of the studies conducted on the relationship between alcohol and cognition have been so in the last 15 years. In general, 
the accumulated literature suggests that acute alcohol intoxication impairs a variety of aspects of cognition, including episodic memory (Tiplady et al., 1999), verbal and spatial learning (Mungas, Ehlers, \& Wall, 1994), and visuospatial attention (Post, Lott, Maddock, \& Beede, 1996). However, the literature also suggests that alcohol's most pronounced effects appear to be on cognitive abilities associated with the prefrontal cortex. In an early study, alcohol significantly impaired tests associated with prefrontal cortex but had a less pronounced effect on tests associated with temporal cortex and did not appear to impair performance on standard intelligence tests (Peterson, Rothfleisch, Zelazo, \& Pihl, 1990). Subsequently, a variety of studies have been conducted, which demonstrate alcohol's specific interference with cognitive capacities thought to be mediated by prefrontal cortex, including attention, abstract reasoning, abstraction, and working memory (Arbuckle, Chaikelson, \& Gold, 1994; Lyvers \& Maltzman, 1991; Sayette, 1994), while leaving abilities such as short-term memory relatively unimpaired (Hoaken, Assaad, \& Pihl, 1998; Tzambasis \& Stough, 2000).

Several of these studies have supported the conclusion of Peterson et al. (1990) that alcohol preferentially affects cognitive abilities thought to be prefrontally mediated. This suggestion appears to be congruous with neuroimaging studies, which suggest that acute alcohol intoxication reduces glucose metabolism predominantly in the prefrontal cortex (de Wit, Metz, Wagner, \& Cooper, 1990; Volkow et al., 1990; Volkow, Wang, \& Doria, 1995).

These lines of research have led researchers to suggest that cognitive interference, specifically interference with what has been called "executive functioning," a higher order cognitive construct subserved by planning, inhibition, active monitoring, and set shifting, mediates the alcohol-aggression relationship (Hoaken, Giancola, \& Pihl, 1998; Giancola, 2000). This theory suggests that when faced with threatening (or even ambiguous) situations, individuals with poor executive function select inappropriate response options, have problems inhibiting behaviors once initiated, and do not adaptively monitor behaviors to assess their appropriateness. While a review of this literature is beyond the scope of this paper (for a comprehensive review, see Giancola, 2000), there does appear to be compelling evidence that the individually specific extent to which alcohol interferes with higher order cognitive capacities is highly predictive of the likelihood of an interpersonally aggressive response (Pihl et al., 2003).

In conclusion, in terms of direct causal relationships between a drug and increased likelihood of interpersonal aggression, there is no doubt that alcohol is culpable. Alcohol seems to lead to violence, to myriad forms of violence, to violence perpetrated by man and by women, by adults and by adolescents, to sexual and nonsexual violence, and to familial and nonfamilial violence. That this relationship exists is incontrovertible. What should now become the focus of research is the development of primary and secondary prevention programming to reduce the costs of alcohol-related violence.

\section{Benzodiazepines}

There is considerable confusion among both the general population and some clinicians regarding the extent to which benzodiazepines lead to violence. While this relationship does 
appear to consistently exist in animals, it is probably better explained by dose and individual difference factors than a pervasive pharmacological effect when it is manifested in humans.

There have been numerous case reports linking benzodiazepines with increased anger and aggression since their introduction in the early 1960's (Dietch \& Jennings, 1988). Given the desired effects of these drugs, specifically to inhibit the anxiety system, this response is theoretically congruous with the effects of alcohol. Contrary to the case reports, the experimental human and animal studies suggest that the amount of violence produced by benzodiazepines pales when compared with that of alcohol. In fact, it is interesting to note that some clinicians have completely dismissed the clinical evidence (Shader \& Greenblatt, 1993) and in fact consider benzodiazepines as antiaggression drugs (Corrigan, Yudofsky, \& Silver, 1993). The issue is obviously consequential, as benzodiazepines are among the most commonly prescribed psychotropic medications (Rivas-Vasquez, 2003). In order to try to reconcile the apparent discrepancy between the two positions, it is important to explore the extent to which individual difference factors and dose-related effects may be important.

The literature demonstrates that benzodiazepines have a heightening effect on aggression, potentially mediated through interference of the anxiety/threat-detection system, an effect that has been demonstrated repeatedly in both animal and human studies (Cherek, Spiga, Roache, \& Cowan, 1991; Commissaris, Hill, McMiller, \& Kleinsorge, 1995; Weisman, Berman, \& Taylor, 1998). However, this effect, shown in research to be statistically significant, may not be clinically significant in the majority of takers. As is sometimes the case, specific individual differences may be the most likely explanation of who does and who does not become meaningfully more aggressive after consumption of a dose of benzodiazepine. A recent study (Ben-Porath \& Taylor, 2002) demonstrated that while a group of men consuming a 10-mg dose of diazepam were more likely to select the most aggressive response on a laboratory measure of aggression than men who had consumed a placebo, it was men who had been shown to have high preexisting levels of hostility that were most susceptible to the effects of the drug. This result was congruous with a review from 10 years previous (Rothschild, 1992), which concluded that when increased aggression is observed after administration of a typical dose of benzodiazepines, some mitigating factor can usually be identified, such as preexisting level of hostility or patient expectation of increased aggressivity. This phenomenon has also been observed in children: A recent study by our group showed that impulsive children administered a benzodiazepines as a preoperative medicant became disinhibited and aggressive at mask induction (Finley, Buffett-Jerrott, Stewart, \& Millington, 2002). Other authors have proposed other mitigating factors, such as preexisting brain damage (French, 1989) or alcohol consumption, which in combination with benzodiazepines has been shown to produce aggression greater than the expected sum of the two drugs (Bond \& Silveira, 1993).

Dose also appears to be an extremely important variable. As mentioned previously, there is considerable disagreement among clinicians regarding whether benzodiazepines are aggression-eliciting or aggression-eliminating drugs. Much of this confusion is likely related to the issue of dose and dose-related effects. The controlled laboratory experiments, which do indeed seem to show benzodiazepine-related increases in aggression, involve relatively low doses, as do the majority of case studies that report disinhibition and/or aggression (Cherek et 
al., 1991; Musik, 1994; Pagano, 1981). Conversely, when benzodiazepines are discussed in the context of psychopharmacological management of aggression, somewhat higher doses are usually involved (Salzman et al., 1991).

\subsection{Opiates (morphine, heroin, and codeine)}

Like benzodiazepines, there is considerable confusion regarding the extent to which opiates are linked to instances of interpersonal aggression. Again like benzodiazepines, a complex interplay of interpersonal and pharmacologic factors (including withdrawal factors) are likely at the root of instances of violence manifested by opiate users and/or abusers.

A large body of literature on the effects of opioids on aggression in animals suggests that morphine and other opium derivatives temporarily reduce aggressive behavior (Espert, Navarro, Salvador, \& Simon, 1993; Haney \& Miczek, 1989; Miczek, Weerts, \& DeBold 1993), although this effect, like many of the effects of opioids, will diminish as tolerance develops (Rodriguez-Arias, Minarro, \& Simon, 2001).

Conversely, controlled studies in humans have demonstrated heightened aggression on laboratory measures of aggression in participants administered both codeine (Spiga, Cherek, Roache, \& Cowan, 1990) and morphine (Berman, Taylor, \& Marged, 1993) relative to controls. However, care must be taken in drawing firm conclusions from these studies. In a more recent study, again using a laboratory measure of aggression, the authors found that heroin-dependent patients (treated with methadone) had higher levels of aggressiveness than healthy controls (Gerra et al., 2001). However, the authors also suggest that the level of aggressiveness demonstrated by the methadone patients seemed to be related more to personality traits than to drug effects. Moreover, a recent study conducted in Spain (Morentin, Callado, \& Meana, 1998), which consisted of a review of the files of 578 recently arrested individuals, concluded that among those arrestees who were heroin abusers, aggression or resistance to police authorities and nonfatal violent offenses against persons were less frequent $(3.7 \%$ and $3 \%$, respectively) than among those arrestees for whom there was no drug or psychiatric diagnosis $(12 \%$ and $13.7 \%$, respectively). Obviously there is some inconsistency in the literature.

What seems more certain is that while intermittent use of opiates seems to produce euphoria and feelings of well-being, chronic administration produces more complex changes in mood and behavior, and an abrupt cessation of opioid administration after tolerance produces a variety of untoward consequences. Opiate withdrawal has consistently been shown to lead to a pattern of behaviors, including heightened aggression in animals (Tidey \& Miczek, 1992), perhaps in part due to heightened pain sensitivity (Miczek et al., 1993). If it is likely that opiate drugs lead to heightened aggression only in individuals with certain personality traits and that it is in fact the absence of heroin that is dangerous after the development of tolerance, then it follows that drugs that block heroin withdrawal should be helpful in the management of aggressive impulses. Although there is some preliminary evidence from the animal literature to suggest that this may be the case (Soderpalm \& Svensson, 1999), studies with humans to assess this possibility have not been conducted. 
When considering the aggression-opiate relationship, perhaps the wisest course of action is to consider characteristics of individuals likely to preferentially abuse opioids. There is some evidence that opioid abusers may have more premorbid feelings of rage (Miczek et al., 1993) and obtain higher in scores of hostility on both self-report (Lindquist, Lindsay, \& White, 1979) and observer-report (Babor et al., 1976) measures. In light of this evidence, it may be the case that individuals who are abusers of opiates are more likely to be aggressive because of the reasons they abuse the drug, not because of the drug itself.

\section{Cannabis}

While cannabis has historically been excoriated for being a social "menace" and for inducing homicidal rages (Julien, 1992), more contemporary research indicates cannabisintoxicated individuals are in fact less likely to act aggressively. However, a developing literature demonstrates an authentic cannabis withdrawal syndrome, one symptom of which may be increased likelihood of interpersonal aggression.

The debate regarding the ills of cannabis dates back decades and rages on today. While most of the contemporary antipathy shown towards cannabis revolves around its controversial status as a "gateway" drug (Fergusson \& Horwood, 2000), cannabis was originally maligned due to its putative aggression-eliciting effects. That belief may have its roots in part in a 1926 article in a New Orleans newspaper exposing the "Menace of Marijuana," an article that claimed an association between the drug and crime, especially violent crime (Julien, 1992), despite the fact that at that time, no experimental evidence on the effects of cannabis on aggression existed. Subscribing to the notion of cannabis as a dangerous drug, the Bureau of Narcotics had soon thereafter established the Marijuana Tax Act, which amounted to a ban of the drug.

Since then, the effects of tetrahydrocannabinol (THC) (the primary psychoactive component of cannabis) on aggressive behavior have been studied at length, with the preponderance of studies focusing on the acute effects of THC intoxication. The results of these studies suggest that while low doses of THC may slightly increase aggression, moderate and high doses can suppress or even eliminate aggressive behavior (Myerscough \& Taylor, 1986; Taylor, 1976). For instance, Taylor et al. (1976) found that aggression manifested on a laboratory measure of aggression by those participants administered a low dose $(0.1 \mathrm{mg} / \mathrm{kg})$ of THC was greater than that manifested by participants in either the medium-dose $(0.25 \mathrm{mg} /$ $\mathrm{kg})$ or high-dose $(0.4 \mathrm{mg} / \mathrm{kg})$ conditions. Moderate doses have also been shown to significantly reduce irritability and verbal hostility in group settings relative to placebo (Salzman, Van Der Kolk, \& Shader, 1976). One study did demonstrate increased aggression in cannabis-intoxicated individuals on a laboratory measure (Cherek et al., 1993), but this study should be interpreted with caution due not only to the small sample size (eight participants), but also to the fact that these participants were "inner city males with extensive drug use histories and self-reported 'antisocial' behavior patterns."

The animal literature also largely fails to support the cannabis-violence relationship; cannabis administration tends to foster submissive behaviors and suppress attack behaviors 
(Miczek, 1978; Sieber, Frischknect, \& Waser, 1980). However, some animal studies, notably those using Wistar rats, have associated increased aggression with cannabis administration. However, careful consideration of these studies indicates that there is usually a third variable, which might account for that finding; for example, REM sleep deprivation (Musty, Lindsey, \& Carlini, 1976), social seclusion (Matte, 1975), or pretreatment with another drug (Fujiwara, Kataoka, Hori, \& Ueki, 1984).

Where cannabis use and aggression may more reliably coexist is within the stillcontroversial notion of the cannabis-withdrawal syndrome (Kouri \& Pope, 2000). Although clinical evidence that such a syndrome exists continues to mount (Budney, Hughes, Moore, \& Novy, 2001; Huestis et al., 2001), the DSM-IV has yet to include marijuana withdrawal as a diagnostic category. Nonetheless, clinicians have described the syndrome as one characterized by restlessness, anorexia, irritability, and insomnia and noted that it can last as long as 1 week to 10 days (Budney, Novy, \& Hughes, 1999; Haney et al., 1999). One study recently demonstrated, using a laboratory measure of aggression, that long-term THC users, tested 3 and 7 days into abstinence, were significantly more aggressive than controls, their own preabstinence behavior, as well as their own behavior at Day 28 of abstinence (Kouri, Pope, \& Lukas, 1999). Thus, it may well be the case that the greatest risk of violence from a user of THC is within the first week of an acute period of abstinence.

\subsection{Psychostimulants (cocaine, amphetamine)}

The psychostimulants are the class of drug with the most idiosyncratic literature regarding their relationship to violence. While mass media representations have convinced most laypeople and many clinicians that these drugs undeniably generate aggression (for a review see Taylor \& Hulsizer, 1998), the experimental literature is largely inconsistent. Interpersonal factors that are preexistent to psychostimulant use and aggression to gain access to these drugs may be better explanations of the relationship than the effects of intoxication.

Although there are several reports in the literature associating the various forms of amphetamine and cocaine use with heightened violence (Brody, 1990; Ellinwood, 1971; Miczek \& Tidey, 1989; Wright \& Klee, 2001), the consistency of this relationship, as well as whether this is the product of a direct pharmacological action, remains in some doubt. While an extensive animal literature indicates that cocaine administered consistently during adolescence will facilitate offensive aggression (i.e., increased number of bites, attacks, and decreased latencies to bite; DeLeon, Grimes, Connor, \& Melloni, 2002; Harrison, Connor, Nowak, \& Melloni, 2000), attack responses do not appear to be a typical or consistent behavioral consequence of the various forms of psychostimulants in unadulterated animals (Field \& Pellis, 1994; Lubin, Meter, Walker, \& Johns, 2001; Miczek \& Haney, 1994; Miczek et al., 1993).

In controlled laboratory studies with humans, amphetamine administration appears to produce increases in competitiveness, excitability, and volubility (Miczek et al., 1993), but these studies are somewhat equivocal as to whether there is a significant increase in aggression (Beezley, Gantner, Bailey, \& Taylor, 1987; Cherek, Kelly, \& Steinberg, 1986; 
Cherek, Steinberg, Kelly, \& Robinson, 1987). The corresponding experimental literature investigating cocaine administration in humans has yet to unequivocally demonstrate a direct link between cocaine administration and increased aggression; only one controlled study has thus far been conducted, and in this study only high dosages of cocaine were associated with increased aggression (Licata, Taylor, Berman, \& Cranston, 1993). Moreover, a recent study that consisted of a retrospective chart review of 311 consecutive psychiatric emergency room patients reported that in that sample, a negative relationship existed; that is, patients with positive toxicology for cocaine were less frequently aggressive than were cocaine-negative patients (Dhossche, 1999), and another emergency room study concluded that aggression in individuals under the influence of cocaine was rare and only occurred if the individual was extremely intoxicated (Brody, 1990).

How then can one reconcile the large number of case reports detailing violence associated with cocaine and amphetamine and the general perception that this relationship exists with the results of these studies? The explanations are likely multifactorial and perhaps predominantly indirect: First, individuals likely to abuse psychostimulants may, for related reasons, be more likely to manifest uninhibited acts of aggression. Antisocial personality and psychopathy have been associated with sensation-seeking, which in turn has been associated with a greater likelihood of initiation of drug use, particularly use of psychomotor stimulants (Pihl \& Peterson, 1992). Recent research has demonstrated that cocaine-dependant subjects who also have antisocial personality disorder were more aggressive than controls; cocaine-dependant individuals without antisocial personality disorder were not more aggressive than controls (Moeller et al., 2002). It has also been suggested that the only individuals likely to act aggressively when intoxicated by amphetamines are those who have preexisting problems with impulse control or aggressive tendencies (Powers \& Kutash, 1978). Second, it is a possibility that the intense psychological dependence associated with these drugs may make users in mild or severe withdrawal more aggressive. One laboratory study did demonstrate that cocaine-dependent subjects were significantly more aggressive than matched controls (Moeller, Steinberg, Petty, \& Fulton, 1994). However, a more recent study of inpatients recently admitted for treatment of cocaine dependence concluded that the level of aggressivity was predicted only by previous aggressive behavior, not cocaine craving, withdrawal symptoms, amount of cocaine used, or length of time since last usage (Moeller et al., 1997). Third, it is also possible that aggression of an instrumental nature may be used in order to attain more of the drug, which by virtue of its illegality is relatively expensive and difficult to procure. Lastly, psychostimulants can increase delusions and hallucinations in patients with psychotic disorders. Because psychosis itself is associated with violence (Hodgins, 1994), individuals with histories of both paranoid delusions and psychostimulant use/abuse must be considered greater risks for violence.

It should also be pointed out that amphetamine has proven effective for the reduction of aggression in hyperactive children and brain-injured adults (Connor \& Steingard, 1996). Clearly, the widely held belief that cocaine and amphetamine lead to heightened aggression is one that is not convincingly supported by the literature. More work is needed to better understand this idiosyncratic relationship between aggression and psychostimulant use, abuse, and withdrawal. 


\section{Phencyclidine (PCP)}

Like the aforementioned psychostimulants, the "reputation" of PCP and the empirical evidence to support that reputation are considerably discrepant. While PCP may indeed lead to violent behavior in some individuals, the effect appears inconsistent and may be explained by factors other than direct pharmacological action.

Although mass media representations would suggest that PCP is the drug most likely to produce a violent "rage," the literature is at best inconsistent (Fauman \& Fauman, 1979; Kinlock, 1991), and one study attempting to demonstrate a causal link between aggression and PCP even went so far as to suggest that clinical and forensic assumptions were "not warranted" (Gillet, Polard, Mauduit, \& Allain, 2001). Research with animals appears to suggest a relationship (Emley \& Hutchinson, 1983; Jarvis, Krieger, \& Cohen, 1985), but findings are somewhat ambiguous. For instance, one study on PCP-related aggression in mice showed that while a dose of PCP increased aggression, it did so only in mice of specific ages and after specific periods of individual housing (Wilmot, Vanderwende, \& Spoerlein, 1987). In another study, where a small dose of PCP caused the treated rat to attack a cohoused animal, a high dose caused the treated animal to be attacked by the cohoused animal (Russell, Greenberg, \& Segal, 1984).

In humans, case reports suggest that violent behavior seems to at least occasionally follow self-administration of PCP (Marrs-Simon, Weiler, Santangelo, Perry, \& Leikin, 1988), but the frequency and intensity of a pharmacological effect, and in fact whether such a relationship truly exists, are at this time in question due to the lack of controlled laboratory studies (Kinlock, 1991). A recent study of PCP users divided participants into groups, one of which had a history of aggression, the other which did not (Fishbein, 1996). This study suggests that a sex difference exists, with men manifesting aggression while PCP-intoxicated and women manifesting aggression between periods of intoxication, a result that would not support a direct pharmacological action. Another study, this one an emergency room study of 33 PCP intoxicated individuals, noted that 11 of the individuals were put into restraints by the nursing staff (Marrs-Simon et al., 1988). However, as the authors themselves note, restraints are administered when the staff believe they may be at risk for violence; it is entirely possible that the nurses were responding not to aggression but to their own expectancies that these individuals would become violent. It is also interesting to note that of the six intoxicants who were women, none were restrained.

Classification of PCP into a drug class is difficult because it is not truly a hallucinogen nor is it truly a psychomotor stimulant, and because its effects are so poorly understood, it is difficult to assess in respects to the systems discussed previously. As with some of the previously discussed drugs, it may be that PCP-related aggression is manifested only in interaction with other variables. One study (McCardle \& Fishbein, 1989) found that personality characteristics and usage history (e.g., age of first administration) were predictive of aggressivity and hostility when participants were asked to retrospectively report behavior while PCP intoxicated. Importantly, it was also found that subjects with a past history of psychiatric hospitalization reported greater levels of committing assault when using PCP than did subjects without psychiatric histories. 


\section{3,4-Methylenedioxymethamphetamine (MDMA; "ecstasy")}

A relatively recent arrival to the recreational drug scene, MDMA, and its association with aggression has nonetheless been the focus of studies in both animals and humans. The extant animal studies have tended to demonstrate that MDMA administration leads to a pattern of "anxiogenic-like" behavior (Maldonado \& Navarro, 2001), characterized by a marked decrease of aggression (threat and attack) as well as decreased social investigation, body care, and digging behaviors. One study, comparing MDMA to two other substances with similar chemical structures and pharmacological properties, d-amphetamine and PCP, suggested that while low doses of the latter two substances would in some animals lead to increases in aggressive behavior, MDMA was never associated with increased aggression and in fact decreased aggression in a dose-dependent manner (Miczek \& Haney, 1994).

While there are no analogous studies in humans (i.e., studies assessing the aggressioneliciting effects of acute MDMA intoxication), there is some concern that long-term use of MDMA may lead to increased propensity for aggression. In one recent study (Gerra et al., 2001), participants with a history of MDMA use and nonuser controls were tested on a laboratory measure of aggression. The authors found that the user group was considerably more aggressive than nonusers and that there was a significant correlation found between the extent to which participants had been exposed to MDMA and aggressive responses $(r=.78$, $P<.001)$. They also found that aggressiveness in the MDMA-using subjects seemed to be associated more with MDMA pharmacological effects than with personality traits. This is an example of a possible neurotoxic effect, but more research is clearly needed to assess this possibility.

\section{Anabolic-androgenic steroids}

Although not typically considered drugs of abuse, anabolic-androgenic steroids appear relevant to the topic at hand because (a) they are often used for nonmedicinal (i.e., recreational) purposes, and (b) numerous retrospective reports propose a link between violence and the use of these drugs (Choi, Parrott, \& Cowan, 1990; Pope \& Katz, 1994; Yates, Perry, \& Murray, 1992). The retrospective nature of the data is problematic, as is the fact that the typical user is a young male athlete, a very specific population, and a population that may well be prone to violence in the first place. An additional confound is the fact that young men are also prone to high levels of drinking; extensive use of alcohol in association with anabolic steroids has been reported in the literature (DuRant, Rickert, Ashworth, Newman, \& Slavens, 1993; Pope \& Katz, 1988).

One review of 13 studies of athletes using steroids found that $34 \%$ of the individuals reported behavioral side effects (Haupt \& Rovere, 1984). Some studies seem to indicate that heavy use seems particularly likely to elicit aggressive reactions (Conacher \& Workman, 1989; Pope \& Katz, 1990), but there are some studies that report negative findings (Bahrke et al., 1990; Bahrke, Wright, Strauss, \& Catlin, 1992). Confusing matters further is the recent suggestion that anabolic-androgenic steroids may act as so-called "gateway" drugs to other 
drugs of abuse, which may themselves have more clear-cut aggression-eliciting properties (Kanayama, Cohane, Weiss, \& Pope, 2003). To better understand the aggression-eliciting properties of anabolic-androgenic steroids, controlled investigations are needed, as well as increased understanding of the endocrinology of aggression.

\section{Conclusions}

Is there a relationship between drugs and aggression? Clearly, the answer is a resounding yes. However, just as clearly, the nature of the relationship is interactional and multifactorial and moreover different for different classes of drug. Moreover, some drugs, at different doses, have paradoxical effects. While there are drugs that undeniably lead to heightened aggression (alcohol), there are others whose reputation for eliciting violence seems unwarranted (PCP). The one thing that can be said unequivocally about the drug-aggression relationship: We do not know enough about it.

According to legislators, one of the reasons drugs are made illegal and the cost of policing and legislating justifiable is to curb the threat of violence. There are two ironies to this. First, the drug we know to be most likely to induce aggressive behavior is not only readily and legally available, it is often sold by the state for profit. Second, the greatest amount of drugrelated violence may be due to the means of regulating an illegal and highly profitable industry (Fagin \& Chin, 1990).

That is not to say at all that currently restricted drugs be made legally available, but instead a call for increased funding for both research and treatment. If we were to better understand what drugs make individuals more aggressive, at what doses, and in what contexts and were we better able to treat addiction, monitoring withdrawal, and associated symptoms, then we may well be able to reduce the enormous costs of drug-related violence. As the appalling crime statistics attest, policing is not enough.

\section{References}

Arbuckle, T. Y., Chaikelson, J. S., \& Gold, D. P. (1994). Social drinking and cognitive functioning revisited: The role of intellectual endowment and psychological distress. Journal of Studies on Alcohol, 55, 352-361.

Babor, T. F., Meyer, R. E., Mirin, S. M., Davies, M., Valentine, N., \& Rawlins, M. (1976). Interpersonal behavior in a small group setting during the heroin addiction cycle. International Journal of the Addictions, 11, 513-523.

Bahrke, M. S., Wright, J. E., O’Conner, J. S., Strauss, R. H., \& Catlin, D. H. (1990). Selected psychological characteristics of anabolic-androgenic steroid users. New England Journal of Medicine, 323(12), 834-835.

Bahrke, M. S., Wright, J. E., Strauss, R. H., \& Catlin, D. H. (1992). Psychological moods and subjectively perceived behavioral and somatic changes accompanying anabolic-androgenic steroid use. American Journal of Sports Medicine, 20(6), 717-724.

Baron, R. A. (1977). Human aggression. New York: Plenum.

Baron, R. A., \& Richardson, D. R. (1994). Human aggression (2nd ed.). New York: Plenum.

Beezley, D. A., Gantner, A. B., Bailey, D. S., \& Taylor, S. P. (1987). Amphetamines and human physical aggression. Journal of Research in Personality, 21(1), 52-60. 
Ben-Porath, D. D., \& Taylor, S. P. (2002). The effects of diazepam (valium) and aggressive disposition on human aggression: An experimental investigation. Addictive Behaviors, 27, 167-177.

Berkowitz, L., \& Thome, P. R. (1987). Pain expectation, negative affect, and angry aggression. Motivation and Emotion, 11, 183-193.

Berman, M., Taylor, S., \& Marged, B. (1993). Morphine and human aggression. Addictive Behaviors, 18(3), $263-268$.

Berry, M. S., \& Smoothy, R. (1986). A critical evaluation of claimed relationships between alcohol intake and aggression in infra-human animals. In P. F. Brain (Ed.), Alcohol and aggression (pp. 84-137). Dover, NH: Croom Helm.

Blanchard, D. C., Blanchard, R. J., \& Rodgers, R. J. (1991). Risk assessment and animal models of anxiety. In B. Olivier, J. Mos, \& J. L. Slangen (Eds.), Animal models in psychopharmacology (pp. 117-134). Boston: Birkhauser Verlag.

Blanchard, D. C., Veniegas, R., Elloran, I., \& Blanchard, R. J. (1993). Alcohol and anxiety: Effects of offensive and defensive aggression. Journal of Studies on Alcohol (Suppl. 11), 9-19.

Blanchard, R. J., Hori, K., Blanchard, D. C., \& Hail, J. (1987). Ethanol effects on aggression of rats selected for different levels of aggressiveness. Pharmacology, Biochemistry \& Behavior, 27, 641-644.

Boileau, I., Assaad, J. M., Pihl, R. O., Benkelfat, C., Leyton, M., Diksic, M., Tremblay, R. E., \& Dagher, A. (2003). Alcohol promotes dopamine release in the human nucleus accumbens. Synapse, 49, 226-231.

Bond, A. J., \& Silveira, J. C. (1993). The combination of alprazolam and alcohol on behavioral aggression. Journal of Studies on Alcohol (Suppl. 11), 30-39.

Brent, D., Perper, J., \& Allman, C. (1987). Alcohol, firearms, and suicide among youth; temporal trends in Allegheny county, Pennsylvania, 1960 to 1983. Journal of the American Medical Association, 257, 3369-3372.

Brody, S. L. (1990). Violence associated with acute cocaine use in patients admitted to a medical emergency department. National Institute on Drug Abuse Research Monograph Series, vol. 103 (pp. 44-59).

Budney, A. J., Hughes, J. R., Moore, B. A., \& Novy, P. L. (2001). Marijuana abstinence effects in marijuana smokers maintained in their home environment. Archives of General Psychiatry, 58, 917-924.

Budney, A. J., Novy, P. L., \& Hughes, J. R. (1999). Marijuana withdrawal among adults seeking treatment for marijuana dependence. Addiction, 94, 1311-1322.

Bushman, B. J. (1993). Human aggression while under the influence of alcohol and other drugs: An integrative research review. Current Directions in Psychological Science, 2(5), 148-152.

Bushman, B. J. (1996). Effects of alcohol on human aggression: Validity of proposed mechanisms. In D. Fuller, R. Dietrich, \& E. Gottheil (Eds.), Recent developments in alcoholism: Alcohol and violence, vol. XIII (pp. 227-243). New York: Plenum.

Bushman, B. J., \& Cooper, H. M. (1990). Effects of alcohol on human aggression: An integrative research review. Psychological Bulletin, 107, 341-354.

Caetano, R., Schafer, J., Fals-Stewart, W., O'Farrell, T., \& Miller, B. (2003). Intimate partner violence and drinking: New research on methodological issues, stability and change, and treatment. Alcoholism, Clinical and Experimental Research, 27, 292-300.

Cherek, D. R., Kelly, T. H., \& Steinberg, J. L. (1986). Behavior contingencies and d-amphetamine effects on human aggressive and non-aggressive responding. National Institute on Drug Abuse Research Monograph Series, 67, 184-189.

Cherek, D. R., Roache, J. D., Egli, M., Davis, C., Spiga, R., \& Cowan, K. (1993). Acute effects of marijuana smoking on aggressive, escape and point-maintained responding of male drug users. Psychopharmacology, 111(2), 163-168.

Cherek, D., Spiga, R., Roache, J., \& Cowan, K. (1991). Effects of triazolam on human aggressive, escape, and point-maintaining responding. Pharmacology, Biochemistry \& Behavior, 40, 835-839.

Cherek, D. R., Steinberg, J. L., Kelly, T. H., \& Robinson, D. (1987). Effects of d-amphetamine on aggressive responding of normal male subjects. Psychiatry Research, 21(3), 257-265.

Chermack, S., \& Giancola, P. (1997). The relationship between alcohol and aggression; an integrated biopsychosocial approach. Clinical Psychology Review, 6, 621-649. 
Chermack, S. T., \& Taylor, S. P. (1993). Barbiturates and human physical aggression. Journal of Research in Personality, 27, 315-327.

Choi, P. Y., Parrott, A. C., \& Cowan, D. (1990). High-dose anabolic steroids in strength athletes: Effects upon hostility and aggression. Human Psychopharmacology, 5, 349-356.

Commissaris, R. L., Hill, T. J., McMiller, L. J., \& Kleinsorge, R. J. (1995). Initial subsensitivity to anxiolytic treatments on conflict behavior in rats: Parametric studies across drug classes. Pharmacology, Biochemistry \& Behavior, 51, 391-396.

Conacher, G. N., \& Workman, D. G. (1989). Violent crime possibly associated with anabolic steroid use. American Journal of Psychiatry, 146(5), 679.

Connor, D. F., \& Steingard, R. J. (1996). A clinical approach to the pharmacotherapy of aggression in children and adolescents. In C. F. Ferris, \& T. Grisso (Eds.), Understanding aggressive behavior in children (pp. 290-307). New York, NY: New York Academy of Sciences.

Conrod, P. J., Peterson, J. B., Pihl, R. O., \& Mankowski, S. (1997). Biphasic effects of alcohol on heart rate are influenced by alcoholic family history and rate of alcohol ingestion. Alcoholism, Clinical and Experimental Research, 21, 140-149.

Corrigan, P., Yudofsky, S., \& Silver, J. (1993). Pharmacological and behavioral treatments for aggressive psychiatric inpatients. Hospital and Community Psychiatry, 44, 125-133.

de Wit, H., Metz, J., Wagner, N., \& Cooper, M. (1990). Behavioral and subjective effects of ethanol: Relationship to cerebral metabolism using PET. Alcoholism, Clinical and Experimental Research, 14, $482-489$.

DeLeon, K. R., Grimes, J. M., Connor, D. F., \& Melloni, R. H. (2002). Adolescent cocaine exposure and offensive aggression: Involvement of serotonin neural signaling and innervation in male Syrian hamsters. Behavioural Brain Research, 133, 211-220.

Dembo, R., Pacheco, K., Schmeidler, J., Fisher, L., \& Cooper, S. (1997). Drug use and delinquent behavior among high risk youths. Journal of Child and Adolescent Substance Abuse, 6, 1-25.

Dietch, J., \& Jennings, R. (1988). Aggressive dyscontrol in patients treated with benzodiazepines. Journal of Clinical Psychiatry, 48, 184-188.

Dhossche, D. M. (1999). Aggression and recent substance abuse: Absence of association in psychiatric emergency room patients. Comprehensive Psychiatry, 40, 343-346.

DuRant, R. H., Rickert, V. I., Ashworth, C. S., Newman, C., \& Slavens, G. (1993). Use of multiple drugs among adolescents who use anabolic steroids. New England Journal of Medicine, 329, 888-889.

Eaton, W. W., Kramer, M., Anthony, J. C., Drymon, A., \& Locke, B. Z. (1989). The incidence of specific DIS/ DSM-III mental disorders: Data from the NIMH Epidemiologic Catchment Area Program. Acta Psychiatrica Scandinavica, 79, 163-178.

Ellinwood, E. H. (1971). Assault and homicide associated with amphetamine abuse. American Journal of Psychiatry, 127, 1170-1175.

Emley, G. S., \& Hutchinson, R. R. (1983). Effects of phencyclidine on aggressive behavior in squirrel monkeys. Pharmacology, Biochemistry \& Behavior, 18, 63-166.

Eronen, M., Hakola, P., \& Tiihonen, J. (1996). Mental disorders and homicidal behavior in Finland. Archives of General Psychiatry, 53, 497-501.

Espert, R., Navarro, J. F., Salvador, A., \& Simon, V. M. (1993). Effects of morphine hydrochloride on social encounters between male mice. Aggressive Behavior, 19(5), 377-383.

Fagan, J., \& Chin, K. L. (1990). Violence as regulation and social control in the distribution of crack. NIDA Research Monograph, 103, 8-43.

Fauman, M. A., \& Fauman, B. J. (1979). Violence associated with phencyclidine abuse. American Journal of Psychiatry, 136, 1584-1586.

Fergusson, D. M., \& Horwood, L. J. (2000). Does cannabis use encourage other forms of illicit drug use? Addiction, 95, 505-520.

Field, E. F., \& Pellis, S. M. (1994). Differential effects of amphetamine on the attack and defense components of play fighting in rats. Physiology \& Behavior, 56, 325-330. 
Finley, G. A., Buffett-Jerrott, S., Stewart, S. H., \& Millington, D. (2002). Effects of midazolam on preoperative anxiety in children. Canadian Journal of Anesthesia, 49, A11.

Fishbein, D. H. (1996). Female PCP-using jail detainees: Proneness to violence and gender differences. Addictive Behaviors, 21, 155-172.

French, A. P. (1989). Dangerously aggressive behavior as a side effect of alprazolam. American Journal of Psychiatry, 146, 276.

Fujiwara, M., Kataoka, Y., Hori, Y., \& Ueki, S. (1984). Irritable aggression induced by D-sup-tetrahydrocannibinol in rats pretreated with 6-hydroxydopamine. Pharmacology, Biochemistry \& Behavior, 20, 457-462.

Gantner, A. B., \& Taylor, S. P. (1988). Human physical aggression as a function of diazepam. Personality and Social Psychology Bulletin, 14, 479-484.

Gerra, G., Zaimovic, A., Ampollini, R., Giusti, F., Delsignore, R., Raggi, M. A., Laviola, G., Macchia, T., \& Brambilla, F. (2001). Experimentally induced aggressive behavior in subjects with 3,4-methylenedioxymethamphetamine ("ecstasy") use history: Psychobiological correlates. Journal of Substance Abuse, 13, 471-491.

Gessa, G. L., Muntoni, F., Collu, M., Vargiu, L., \& Mereu, G. (1985). Low doses of ethanol activate dopaminergic neurons in the ventral tegmental area. Brain Research, 348, 201-203.

Giancola, P. R. (2000). Executive functioning: A conceptual framework for alcohol-related aggression. Experimental and Clinical Psychopharmacology, 8, 576-597.

Giancola, P. R., Helton, E. L., Osborne, A. B., Terry, M. K., Fuss, A. M., \& Westerfield, J. A. (2002). The effects of alcohol and provocation on aggressive behavior in men and women. Journal of Studies on Alcohol, 63, 64-73.

Gillet, C., Polard, E., Mauduit, N., \& Allain, H. (2001). Acting out and psychoactive substances: Alcohol, drugs, illicit substances. Encephale, 27, 351-359.

Gray, J. A. (1982). The neuropsychology of anxiety: An enquiry into the function of the septo-hippocampal system. New York: Oxford University Press.

Gray, J. A. (1987). The psychology of fear and stress (2nd ed.). New York: Cambridge University Press.

Gustafson, R. (1985). Alcohol and aggression: A validation study of the Taylor aggression paradigm. Psychological Reports, 57, 667-676.

Haney, M., \& Miczek, K. A. (1989). Morphine effects on maternal aggression, pup care, and analgesia in mice. Psychopharmacology, 98, 68-74.

Haney, M., Ward, A. S., Comer, S. D., Hart, C. L., Foltin, R., \& Fischman, M. (1999). Abstinence symptoms following smoked marijuana in humans. Psychopharmacology, 141, 395-404.

Harrison, R. J., Connor, D. F., Nowak, C., \& Melloni, R. H. (2000). Chronic low-dose cocaine treatment during adolescence facilitates aggression in hamsters. Physiology \& Behavior, 69, 555-562.

Haupt, H. A., \& Rovere, G. D. (1984). Anabolic steroids: A review of the literature. American Journal of Sports Medicine, 12, 468-484.

Hoaken, P. N. S., Assaad, J. M., \& Pihl, R. O. (1998). Cognitive functioning and the inhibition of alcoholinduced aggression. Journal of Studies on Alcohol, 59, 599-607.

Hoaken, P. N. S., Campbell, T., Stewart, S., \& Pihl, R. O. (2003). Effects of alcohol on cardiovascular reactivity and the mediation of aggressive behaviour in adult men and women. Alcohol and Alcoholism, $38,84-92$.

Hoaken, P. N. S., Giancola, P., \& Pihl, R. O. (1998). Executive cognitive functions as mediators of alcoholrelated aggression. Alcohol and Alcoholism, 33, 47-54.

Hoaken, P. N. S., \& Pihl, R. O. (2000). The effects of alcohol intoxication on aggressive responses in men and women. Alcohol and Alcoholism, 35, 471-477.

Hodgins, S. (1994). Schizophrenia and violence: Are new mental health policies needed? Journal of Forensic Psychiatry, 5, 473-477.

Hodgins, S., Mednick, S. A., Brennan, P. A., Schulsinger, F., \& Engberg, M. (1996). Mental disorder and crime. Evidence from a Danish birth cohort. Archives of General Psychiatry, 53, 489-496.

Huestis, M. A., Gorelick, D. A., Heishman, S. J., Preston, K. L., Nelson, R. A., Moolchan, E. T., \& Frank, R. A. 
(2001). Blockade of effects of smoked marijuana by the CB1-selective cannabinoid receptor antagonist SR141716. Archives of General Psychiatry, 58, 322-328.

Hull, J. (1981). A self-awareness model of the causes and effects of alcohol consumption. Journal of Abnormal Psychology, 90, 586-600.

Hull, J., \& Bond, C. (1986). Social and behavioral consequences of alcohol consumption and expectancy: A metaanalysis. Psychological Bulletin, 99, 347-360.

Ito, T. A., Miller, N., \& Pollock, V. E. (1996). Alcohol and aggression: A meta-analysis on the moderating effects of inhibitory cues, triggering events, and self-focused attention. Psychological Bulletin, 120, 60-82.

Jarvis, M. F., Krieger, M., \& Cohen, G. (1985). The effects of phencyclidine and chlordiazepoxide on target biting of confined male mice. Aggressive Behavior, 11(3), 201-205.

Julien, R. M. (1992). A primer of drug action. New York: Freeman.

Kanayama, G., Cohane, G. H., Weiss, R. D., \& Pope, H. G. (2003). Past anabolic-androgenic steroid use among men admitted for substance abuse treatment: An under-recognized problem? Journal of Clinical Psychiatry, 64, 156-160.

Kaufman-Kantor, G., \& Straus, M. (1990). Parental drinking and violence and child aggression. Paper presented at the 98th Annual Convention of the American Psychological Association, Boston, MA.

Kinlock, T. W. (1991). Does phencyclidine (PCP) use increase violent crime? Journal of Drug Issues, 21, $795-816$.

Kouri, E. M., \& Pope, H. G. (2000). Abstinence symptoms during withdrawal from chronic marijuana use. Experimental and Clinical Psychopharmacology, 8, 483-492.

Kouri, E. M., Pope, H. G., \& Lukas, S. E. (1999). Changes in aggressive behavior during withdrawal from longterm marijuana use. Psychopharmacology, 143, 302-308.

Leonard, K. E., \& Jacob, T. (1988). Alcohol, alcoholism, and family violence. In V. B. Van Hasselt, R. L. Morrison, A. Bellack, \& M. Hersen (Eds.), Handbook of family violence (pp. 383-406). New York: Plenum.

Leonard, K. E., \& Senchak, M. (1996). Prospective prediction of husband marital aggression within newlywed couples. Journal of Abnormal Psychology, 105, 369-380.

Licata, A., Taylor, S., Berman, M., \& Cranston, J. (1993). Effects of cocaine on human aggression. Pharmacology, Biochemistry \& Behavior, 45(3), 549-552.

Lindquist, C. U., Lindsay, J. S., \& White, G. D. (1979). Assessment of assertiveness in drug abusers. Journal of Clinical Psychology, 35, 676-679.

Lubin, D. A., Meter, K. E., Walker, C. H., \& Johns, J. M. (2001). Effects of chronic cocaine administration on aggressive behavior in virgin rats. Progress in Neuro-Psychopharmacology \& Biological Psychiatry, 25, $1421-1433$.

Lyvers, M. F., \& Maltzman, I. (1991). Selective effects of alcohol on Wisconsin card sorting test performance. British Journal of Addiction, 86, 399-407.

Maldonado, E., \& Navarro, J. F. (2001). MDMA ("ecstasy") exhibits an anxiogenic-like activity in social encounters between male mice. Pharmacological Research, 44, 27-31.

Marrs-Simon, P. A., Weiler, M., Santangelo, M. A., Perry, M. T., \& Leikin, J. B. (1988). Analysis of sexual disparity of violent behavior in PCP intoxication. Veterinary and Human Toxicology, 30, 53-55.

Matte, A. C. (1975). Effects of hashish on isolation induced aggression in wild mice. Psychopharmacologia, 45(1), $125-128$.

McCardle, L., \& Fishbein, D. H. (1989). The self-reported effects of PCP on human aggression. Addictive Behaviors, 14, 465-472.

Miczek, K. A. (1978). D-sup-tetrahydrocannibinol: Antiaggressive effects in mice, rats, and squirrel monkeys. Science, 199(4336), 1459-1461.

Miczek, K. A., deBold, J. F., Haney, M., Tidey, J., Vivian, J., \& Weerts, E. M. (1993). Alcohol, other psychoactive drugs, and violence. In A. J. Reiss, \& J. A. Roth (Eds.), Understanding and preventing violence. Social influences, vol. 3 (pp. 182-220). Washington, DC: National Academy Press.

Miczek, K. A., \& Haney, M. (1994). Psychomotor stimulant effects of d-amphetamine, MDMA and PCP: Aggressive and schedule-controlled behavior in mice. Psychopharmacology, 115, 358-365. 
Miczek, K. A., \& Tidey, J. W. (1989). Amphetamines: Aggressive and social behavior. National Institute on Drug Abuse Research Monograph Series, 94, 68-100.

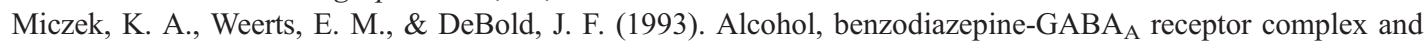
aggression: Ethological analysis of individual differences in rodents and primates. Journal of Studies on Alcohol (Suppl. 11), 170-179.

Moeller, F. G., Dougherty, D. M., Barratt, E. S., Oderinde, V., Mathias, C. W., Harper, R. A., \& Swann, A. C. (2002). Increased impulsivity in cocaine dependent subjects independent of antisocial personality disorder and aggression. Drug and Alcohol Dependence, 68, 105-111.

Moeller, F. G., Dougherty, D. M., Rustin, T., Swann, A. C., Allen, T. J., Shah, N., \& Cherek, D. R. (1997). Antisocial personality disorder and aggression in recently abstinent cocaine dependent subjects. Drug and Alcohol Dependence, 44, 175-182.

Moeller, F. G., Steinberg, J. L., Petty, F., \& Fulton, M. (1994). Serotonin and impulsive/aggressive behavior in cocaine dependent subjects. Progress in Neuro-Psychopharmacology \& Biological Psychiatry, 18(6), $1027-1035$.

Morentin, B., Callado, L. F., \& Meana, J. J. (1998). Differences in criminal activity between heroin abusers and subjects without psychiatric disorders: Analysis of 578 detainees in Bilbao, Spain. Journal of Forensic Sciences, 43, 993-999.

Mullin, F. J., \& Luckhardt, A. B. (1934). The effect of alcohol on cutaneous tactile and pain sensitivity. American Journal of Physiology, 109, 7-78.

Mungas, D., Ehlers, C. L., \& Wall, T. L. (1994). Effects of acute alcohol administration on verbal and spatial learning. Alcohol and Alcoholism, 29, 163-169.

Murdoch, D., Pihl, R. O., \& Ross, D. (1990). Alcohol and crimes of violence: Present issues. International Journal of the Addictions, 25, 1065-1081.

Musik, K. (1994). Effect of diazepam and provocation of human aggression. Unpublished doctoral dissertation. Kent State University, Kent, $\mathrm{OH}$.

Musty, R. E., Lindsey, C. J., \& Carlini, E. A. (1976). 6-Hydroxydomapine and the aggressive behavior induced by marihuana in REM sleep-deprived rats. Psychopharmacology, 48(2), 175-179.

Myerscough, R., \& Taylor, S. P. (1986). The effects of marijuana on human physical aggression. Journal of Personality and Social Psychology, 49(6), 1541-1546.

Pagano, M. R. (1981). The effects of diazepam (valium) on human physical aggression. Unpublished doctoral dissertation. Kent State University, Kent, $\mathrm{OH}$.

Parks, K. A., \& Zetes-Zanatta, L. M. (1999). Women's bar-related victimization: Refining and testing a conceptual model. Aggressive Behavior, 25, 349-364.

Peterson, J. B., Rothfieisch, J., Zelazo, P. D., \& Pihl, R. O. (1990). Acute alcohol intoxication and cognitive functioning. Journal of Studies on Alcohol, 51, 114-122.

Pihl, R. O., Assaad, J. M., \& Hoaken, P. N. S. (2003). The alcohol-aggression relationship and differential sensitivity to alcohol. Aggressive Behavior, 29, 302-315.

Pihl, R. O., \& Hoaken, P. N. S. (1997). Clinical correlates and predictors of violence in patients with substance use disorders. Psychiatric Annals, 27(11), 735-740.

Pihl, R. O., \& Hoaken, P. N. S. (2002). Biological bases to addiction and aggression in close relationships. In C. Wekerle, A. M. Wall (Ed.), The violence and addiction equation: Theoretical and clinical issues in substance abuse and relationship violence (pp. 25-43). Philadelphia, PA: Brunner/ Mazel.

Pihl, R. O., \& Peterson, J. B. (1992). Etiology. In P. E. Nathan, J. W. Langenbucher, B. S. McCrady, \& W. Frankenstein (Eds.), Annual review of addiction research and treatment (pp. 153-175). Elmsford, NY: Pergamon.

Pihl, R. O., \& Peterson, J. B. (1995). Drugs and aggression: Correlations, crime and human manipulative studies and some proposed mechanisms. Journal of Psychiatry \& Neuroscience, 20(2), 141-149.

Pihl, R. O., Peterson, J. B., \& Lau, M. A. (1993). A biosocial model of the alcohol-aggression relationship. Journal of Studies on Alcohol (Suppl. 11), 128-139. 
Pope, H. G., \& Katz, D. L. (1988). Affective and psychotic symptoms associated with anabolic steroid use. American Journal of Psychiatry, 145, 487-490.

Pope, H. G., \& Katz, D. L. (1990). Homicide and near-homicide by anabolic steroid users. Journal of Clinical Psychiatry, 51(1), 28-31.

Pope, H. G., \& Katz, D. L. (1994). Psychiatric and medical effects of anabolic-androgenic steroid use: A controlled study of 160 athletes. Archives of General Psychiatry, 51(5), 375-382.

Post, R. B., Lott, L. A., Maddock, R. J., \& Beede, J. I. (1996). An effect of alcohol on the distribution of spatial attention. Journal of Studies on Alcohol, 57, 260-266.

Powers, R., \& Kutash, I. (1978). Substance-induced aggression. In I. Kutash, S. Kutash, \& L. Schlesinger (Eds.), Violence: Perspective on murder and aggression (pp. 317-342). San Francisco: Jossey-Bass.

Rivas-Vasquez, R. A. (2003). Benzodiazepines in contemporary clinical practice. Professional Psychology: Research \& Practice, 34, 324-328.

Rodriguez-Arias, M., Minarro, J., \& Simon, V. M. (2001). Development of tolerance to the anti-aggressive effects of morphine. Behavioral Pharmacology, 12, 221-224.

Rothschild, A. J. (1992). Disinhibition, amnestic reactions, and other adverse reactions secondary to triazolam: A review of the literature. Journal of Clinical Psychiatry, 53(Suppl. 12), 69-79.

Rush, C. R., Higgins, S. T., Hughes, J. R., Bickel, W. K., \& Wiegner, M. S. (1989). Acute behavioral and cardiac effects of alcohol and caffeine, alone and in combination, in humans. Behavioural Pharmacology, 4, 562-572.

Russell, J. W., Greenberg, B. D., \& Segal, D. S. (1984). The effects of phencyclidine on spontaneous aggressive behavior in the rat. Biological Psychiatry, 19(2), 195-202.

Salzman, C., Solomon, D., Miyawaki, E., Glassman, R., Rood, L., Flowers, E., \& Thayer, S. (1991). Parenteral lorazepam versus parenteral haloperidol for the control of psychotic disruptive behavior. Journal of Clinical Psychiatry, 52(4), 177-180.

Salzman, C., Van Der Kolk, B. A., \& Shader, R. I. (1976). Marijuana and hostility in a small-group setting. American Journal of Psychiatry, 133, 1029-1033.

Sayette, M. A. (1993a). An appraisal-disruption model of alcohol's effects on stress responses in social drinkers. Psychological Bulletin, 114, 459-476.

Sayette, M. A. (1993b). Heart rate as an index of stress response in alcohol administration research: A critical review. Alcoholism, Clinical and Experimental Research, 17, 802-809.

Sayette, M. A., Wilson, G. T., \& Elias, M. J. (1993). Alcohol and aggression: A social information processing analysis. Journal of Studies on Alcohol, 54, 399-407.

Sayette, M. A. (1994). Effects of alcohol on self-appraisal. International Journal of the Addictions, 29, 127-133.

Seto, M., \& Barbaree, H. (1995). The role of alcohol in sexual aggression. Clinical Psychology Review, 15, $545-566$.

Shader, R., \& Greenblatt, J. (1993). Use of benzodiazepines in anxiety disorders. New England Journal of Medicine, 328, 1398-1405.

Sieber, B., Frischknect, H., \& Waser, P. G. (1980). Behavioral effects of hashish in mice: III. Social interactions between two residents and an intruder male. Psychopharmacology, 70(3), 273-278.

Soderpalm, B., \& Svensson, A. I. (1999). Naloxone reverses disinhibitory/aggressive behavior in 5,7-DHTlesioned rats; involvement of GABA(A) receptor blockade? Neuropharmacology, 38, 1851-1859.

Spiga, R., Cherek, D. R., Roache, J. D., \& Cowan, K. A. (1990). The effects of codeine on human aggressive responding. International Clinical Psychopharmacology, 5(3), 195-204.

Steele, C. M., \& Josephs, R. A. (1990). Alcohol myopia: Its prized and dangerous effects. American Psychologist, 45, 921-933.

Steele, C. M., \& Southwick, L. (1985). Alcohol and social behaviour: I. The psychology of drunken excess. Journal of Personality and Social Psychology, 48, 18-34.

Stewart, S. H., Loba, P., Blackburn, J. R., Ellery, M., \& Klein, R. M. (in press). Heart rate increase to alcohol administration and video lottery terminal (VLT) play. Psychology of Addictive Behaviors.

Taylor, S., Vardaris, R., Rawich, A., Gammon, C., Cranston, J., \& Lubetkin, A. I. (1976). The effects of alcohol and delta-9-tetrahydrocannabinol on human physical aggression. Aggressive Behavior, 2, 153-161. 
Taylor, S. P. (1967). Aggressive behaviour and physiological arousal as a function of provocation and the tendency to inhibit aggression. Journal of Personality, 35, 297-310.

Taylor, S. P. (1976). The effects of alcohol and delta-9-tetrahydrocannibinol on human physical aggression. Aggressive Behavior, 2(2), 153-161.

Taylor, S. P., \& Hulsizer, M. R. (1998). Psychoactive drugs and human aggression. In R. G. Geen, \& E. Donnerstein (Eds.), Human aggression: Theories, research, and implications for social policy (pp. 139-165). San Diego, CA: Academic Press.

Taylor, S. P., \& Leonard, K. E. (1983). Alcohol and human physical aggression. In R. G. Geen, \& E. I. Donnerstein (Eds.), Aggression: Theoretical and empirical reviews, vol. 2 (pp. 77-101). San Diego, CA: Academic Press.

Testa, M. (2002). The impact of men's alcohol consumption on perpetration of sexual aggression. Clinical Psychology Review, 22, 1239-1263.

Tidey, J. W., \& Miczek, K. A. (1992). Heightened aggressive behavior during morphine withdrawal: Effects of d-amphetamine. Psychopharmacology, 107, 297-302.

Tiplady, B., Harding, C., McLean, D., Ortner, C., Porter, K., \& Wright, P. (1999). Effects of ethanol and temazepam on episodic and semantic memory: A dose-response comparison. Human Psychopharmacology, $14,263-269$.

Tzambazis, K., \& Stough, C. (2000). Alcohol impairs speed of information processing and simple and choice reaction time and differentially impairs higher-order cognitive abilities. Alcohol and Alcoholism, 35, 197-201.

Valdes, A., Kaplan, C., Curtis, R., \& Yin, Z. (1995). Illegal drug use, alcohol and aggressive crime among Mexican American and White male arrestees in San Antonio. Journal of Psychoactive Drugs, 27, 135-143.

Volkow, N. D., Hitzemann, R., Wolf, A., Logan, J., Fowler, J., Christman, D., Dewey, S., Schlyer, D., Burr, G., Vitkun, S., \& Hirschowitz, J. (1990). Acute effects of ethanol on regional brain glucose metabolism and transport. Psychiatry Research, 35, 39-48.

Volkow, N. D., Wang, G., \& Doria, J. (1995). Monitoring the brain's response to alcohol with positron emission tomography. Alcohol Health and Research World, 19, 296-299.

Weisman, A. M., Berman, M. E., \& Taylor, S. P. (1998). Effects of clorazepate, diazepam, and oxazepam on a laboratory measurement of aggression in men. International Clinical Psychopharmacology, 13, 183-188.

Wilmot, C. A., Vanderwende, C., \& Spoerlein, M. T. (1987). The effects of phencyclidine on fighting in differentially housed mice. Pharmacology, Biochemistry \& Behavior, 28(3), 341-346.

Wolff, H. G., Hardy, J. D., \& Goodell, H. (1942). Studies on pain: Measurement of the effect of ethyl alcohol on the pain threshold and on the "alarm reaction". Journal of Pharmacology, 75, 38-49.

Wright, S., \& Klee, H. (2001). Violent crime, aggression and amphetamine: What are the implications for drug treatment services? Drugs: Education, Prevention Policy, 8, 73-90.

Yates, W. R., Perry, P., \& Murray, S. (1992). Aggression and hostility in anabolic steroid users. Biological Psychiatry, 31, 1232-1234. 